\title{
6. Biocatalysis on porous materials
}

Isabel Díaz, Rosa María Blanco, Manuel Sánchez-Sánchez, Carlos Márquez-Álvarez Instituto de Catálisis y Petroleoquímica (CSIC)

\begin{abstract}
Enzyme-based processes are gaining ground in applied industrial catalysis. The exploitation of the biocatalytic activity of enzymes in a massive context ineludibly implies their heterogeneization and/or immobilization on solid supports whereas their catalytic efficiency is maintained at some extent. Since the catalytic role of enzymes is directly related to their quaternary/tertiary structure, the non-covalent immobilization strategies normally become more effective. This Chapter deals with several methods for encapsulating enzymes within porous materials developed by our group in the last decade. Apart from the non-covalent nature of the enzyme-support interaction, the encapsulation of enzymes provides some extra key advantages: (i) the resultant solid biocatalysts can take advantage of the size sieving of the reactants and products provided by the supports; (ii) the both kinds of studied supports, i.e. $\mathrm{SiO}_{2}$ - or organosilica-based ordered mesoporous materials (OMM) and metal-organic framework (MOF) materials, can be easily and controllably functionalized by organic groups favoring the immobilization efficiency and preventing the enzyme leaching; (iii) the pore arrangement of the supports can be tailored to the enzyme requirements, such as the use of cage/window mesoporous system allowing the in-situ encapsulation of enzymes with no subsequent leaching at all. All these strategies have been widely and successfully developed for OMMs materials, although it is recommendable to optimize the physicochemical properties of the OMM support for any particular enzyme. On the contrary, the use of MOFs as supports of enzymes is relatively new, especially the universal approaches in which the MOF materials do not need to have pore larger than the enzyme to be immobilized. The very rich compositional, structural and functionalization versatility of these porous supports entails a very promising future for the enzyme immobilization.
\end{abstract}

Keywords: Enzymes, immobilization, porous solids, mesoporous materials, OMM, lipase, laccase, MOF 


\section{Introduction}

The wide variety of reactions catalysed in nature in a selective fashion and under mild conditions makes enzymes the potential ideal catalysts for industrial use. Enzymes application, however, is limited by their lability and solubility, and therefore the first step to achieve this goal is to make them insoluble. This can be achieved using several approaches (Figure 1), which include the formation of enzyme agglomerates by crosslinking using bifunctional linkers that react with amino acid residues, trapping of enzymes within polymer networks and binding of enzymes to solid supports. In the latter case, immobilization can be carried out either by covalent attachment or by adsorption on porous solids, and innumerable materials have been used as supports, of any imaginable origin or chemical nature [1-9].

\section{cross-linking}

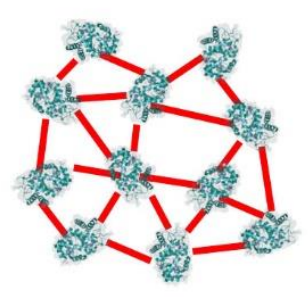

adsorption

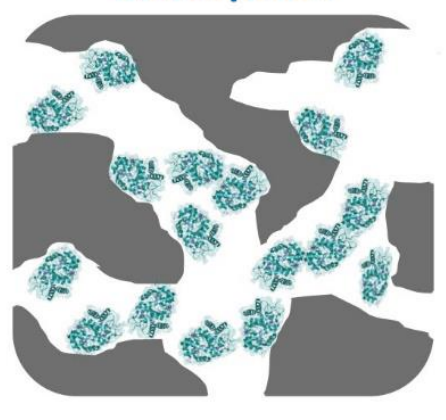

\section{entrapment}

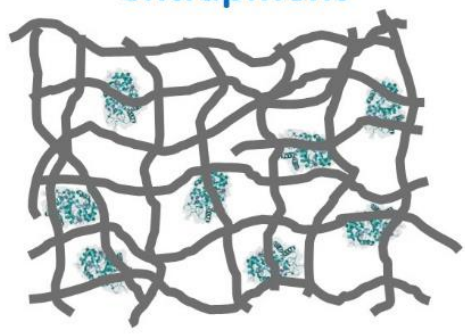

covalent bonding

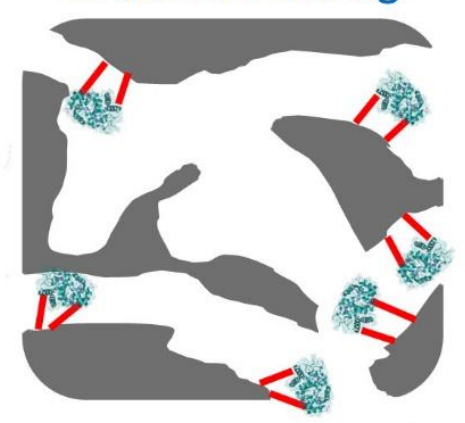

Figure 1. Different approaches employed to make enzymes insoluble.

From the last decade, special attention has been paid to the material used, particularly the development of Ordered Mesoporous Materials (OMM) $[10,11]$ as an alternative to the classical sol-gel entrapment. The advantageous features of the OMM over the previously available amorphous mesoporous silicas prepared by conventional sol-gel methods make them potentially ideal enzyme carriers. Especially, the optimum control of the textural 
properties allows designing and customizing the mesostructure for specific applications. This possibility was explored soon, and since the pioneer works by Balkus et al. in 1996 [12] many different enzymes have been encapsulated in OMM [13].

\subsection{Zeolites versus Ordered Mesoporous Materials}

In biocatalysis, the catalytic active site is part of an enzyme, which is a macromolecule of large dimensions ranging from 100 to 500 amino acids long. Bearing this in mind, supporting enzymes in porous matrices to yield a heterogeneous catalyst requires the confinement of macromolecules within pores in the same size-range. In this scenario, zeolites, with pore sizes below the nanometer range, have been tested as supports of enzymes using basically the outer surface of the zeolite crystals. Some good reports can be found in which delaminated zeolites $[14,15]$ or pillared lamellar precursors of zeolites [16] were tested as biocatalyst supports. Delaminated zeolites become good enzyme supports due to their high surface area, to which the enzymes may be anchored via electrostatic interactions, or even covalent bonding. In this manner, supporting enzymes on zeolites potentially solves the drawbacks that are usually associated to encapsulation via sol-gel, such as enzyme aggregation and poor pore connectivity. However, this approach brought limitations in leaching, conformation and deactivation of the enzymes.

Nowadays, mesoporous silica structures can be fine-tuned controlling the synthesis conditions, using micelles of cationic, anionic or non-ionic surfactants as templates. The choice of the surfactant rules the $\mathrm{pH}$ of the synthesis gel in a way that further controls the hydrolysis and condensation of the silica source that will form the walls of the porous architecture. Cationic and anionic surfactants usually work well in forming mesoporous silica phases at high $\mathrm{pH}$, typically above 9 . At high $\mathrm{pH}$, silica would be negatively charged creating electrostatic interactions with the cationic surfactant micelles leading the formation of the amorphous pore walls. Thus, in the early works, Ordered Mesoporous Materials were synthesized purely as aluminosilicates, using cationic surfactants in highly alkaline media [17]. Later on, anionic surfactants were employed and then aminosilane precursors owed to be used in order to provide with a positive charge at $\mathrm{pH}$ above 8 [18]. It could be said that nowadays, the most widely reported OMM are those prepared using non-ionic block copolymer surfactants. These surfactants are commonly based on 
polyethylene and polypropylene chains and thus, they aggregate efficiently in robust micelles only at very acidic $\mathrm{pH}$, even below $\mathrm{pH} 1$, at which the silica is positively charged and condensation takes place assembling with the micelles via hydrogen bonds. The wide variety of synthesis conditions based on non-ionic surfactants has covered a full range of symmetries as well as pore sizes [19]. In any case, due to the sensitive nature of enzymes, the drastic synthesis conditions require that the immobilization be limited only to a postsynthesis approach, i.e., the OMM has to be prepared in a first step, the surfactant has to be removed, and then the enzyme can be allocated inside the pores of the OMM. This approach was initially limited to (and tested with) enzymes that could fit in the obtained pore sizes, and those that could somehow interact with a pore surface made of amorphous silica. This strategy has now been reversed, and what we intend to show in the next few pages is how it is possible to design the right OMM support for a particular enzyme of a certain size and properties, using chemical affinities and confined space while maintaining biocatalytic activity. Furthermore, we have developed the synthesis methods commonly employed for OMM in order to obtain this kind of heterogeneous biocatalysts by an in situ immobilization route [20].

This possibility to design the solid matrix according to the characteristics of the enzyme is the key that has enabled a step ahead towards a second generation of enzyme supports, providing improved properties to the obtained biocatalysts [11, 21-23]. Compared to the microporosity of zeolites, in which the pore sizes are below $1.5 \mathrm{~nm}$, Ordered Mesoporous Materials show pores which size ranges from 2.5 to $10 \mathrm{~nm}$, or even more, by exploiting the use of surfactant micelles and micelle expanders as structure directing agents (Figure 2). Pore architectures formed by channels or cages can be easily designed during the synthesis process leading to tunable diffusion properties (Figure 3).

Besides the pore size, the structure of OMM is characterized by the amorphous nature of the pore framework as opposed to the crystallinity of zeolites, and finally a more flexible and versatile chemistry in these pore walls. The amorphous nature of the silicate framework leads to the presence of high number of defects, i.e., non-condensed silanol groups, with increased presence of these $\mathrm{OH}$ groups on the pore surface, which can be further used as anchoring point for functional groups. Surface functionalization has been widely reported. The versatility of alcoxysilane sources gives a wide range of functionalities as potential interactions for further immobilization of enzymes [24]. Two 


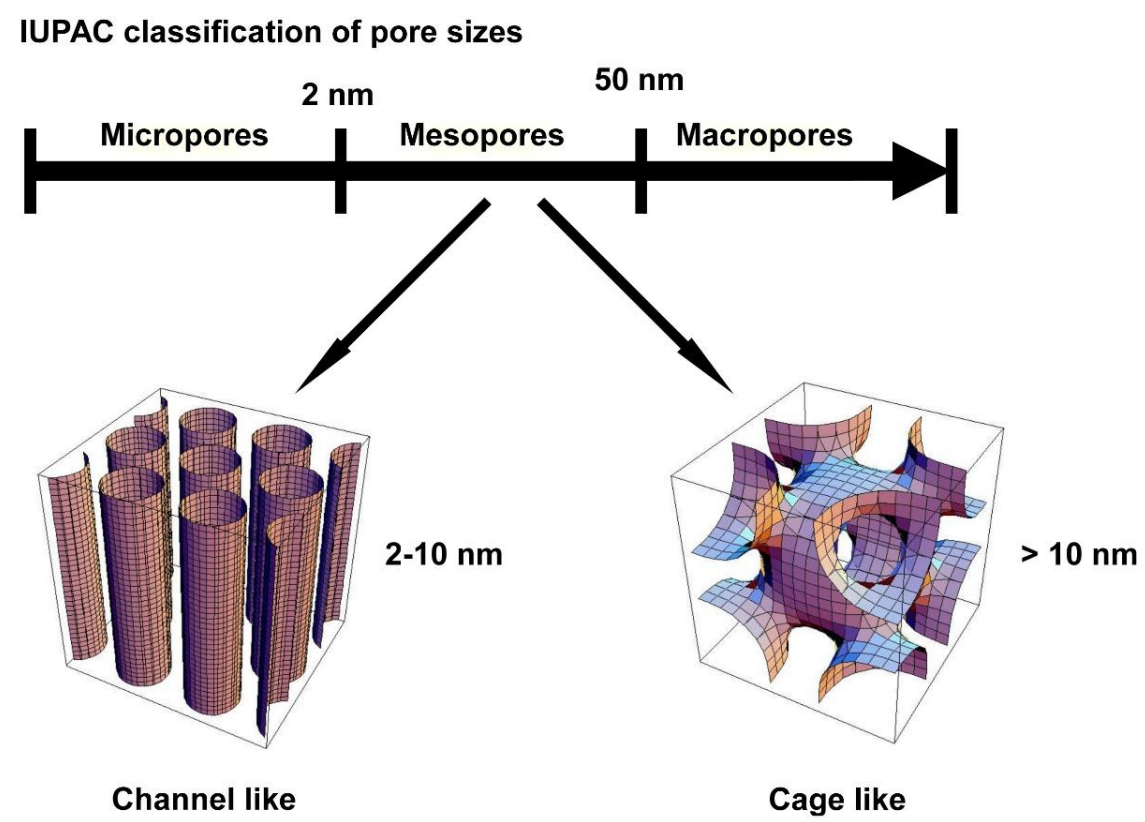

Figure 2. Classification of porous solids.

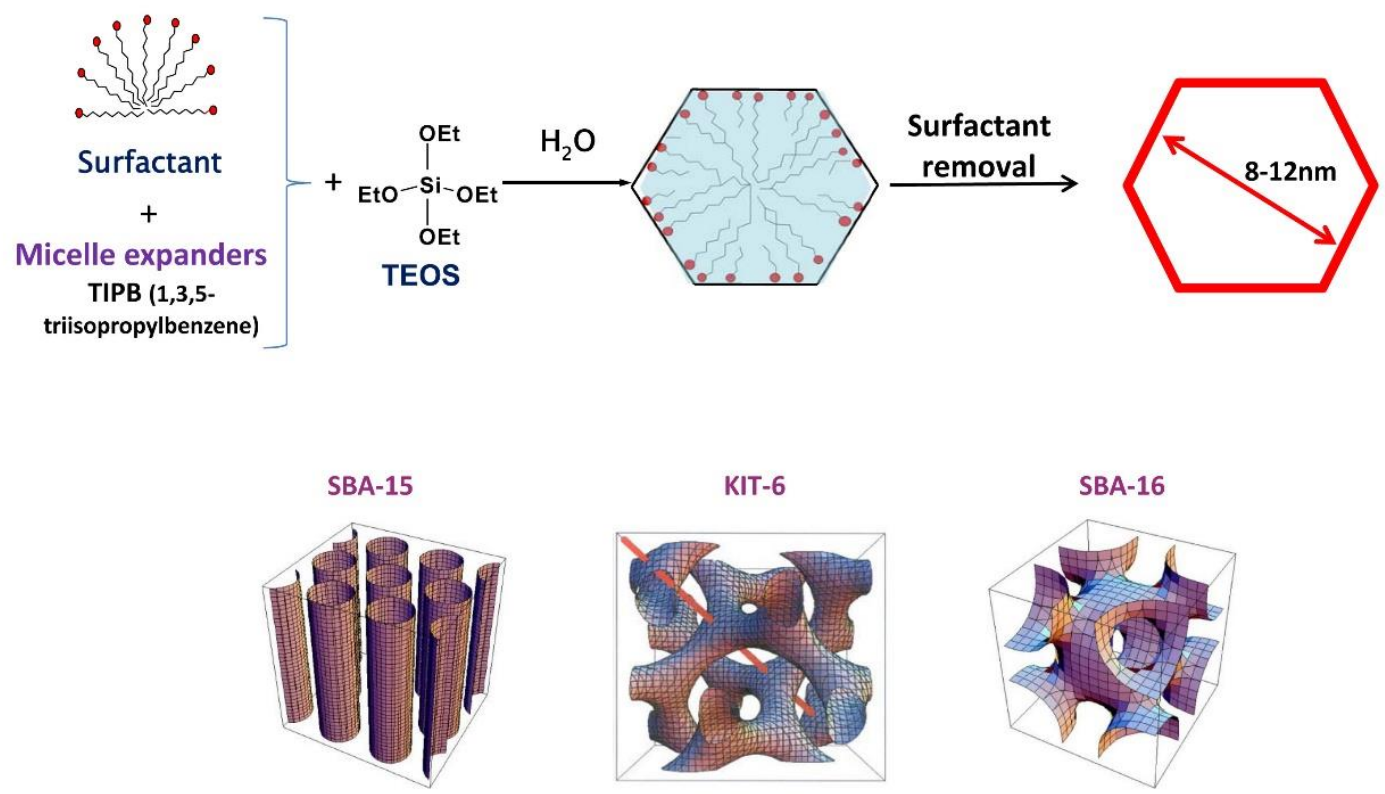

Figure 3. General synthesis procedure of Ordered Mesoporous Materials.

approaches could be used for including functional groups to the pore surface of OMM: grafting and co-condensation (Figure 4). Grafting refers to a two-step process in which first the OMM is synthesized to further react with an organosilane holding the desired functional group. The advantages of this method refers to the amount of functional group 
that can be incorporated that is mainly restricted by the number of $\mathrm{OH}$ available on the surface; however, the chemistry of this functionalization reveals that the process is very sensitive to the reaction conditions and the pore size of the OMM. The alcoxysilane has to diffuse way inside the pores to anchor. Therefore, the distribution of functionalities along the pore surface may not be even or homogeneous. Finally, in this method, the grafting of functionalities implies a decrease in the final available pore size. In the cocondensation approach, the organosilane is incorporated in the material during the synthesis of the OMM. In this manner, the functionalities are already incorporated while interacting with the surfactant micelles which are the pore directing agents. On the other hand, given the necessity of the silica-surfactant interaction to obtain a structured OMM, the number of functional groups should not be higher than $10 \%$ of the total silicon atoms. Furthermore, this type of functionalization is restricted to functional groups that will not alter the chemistry of the silica-surfactant interactions at the synthesis conditions $(\mathrm{pH}<1)$.

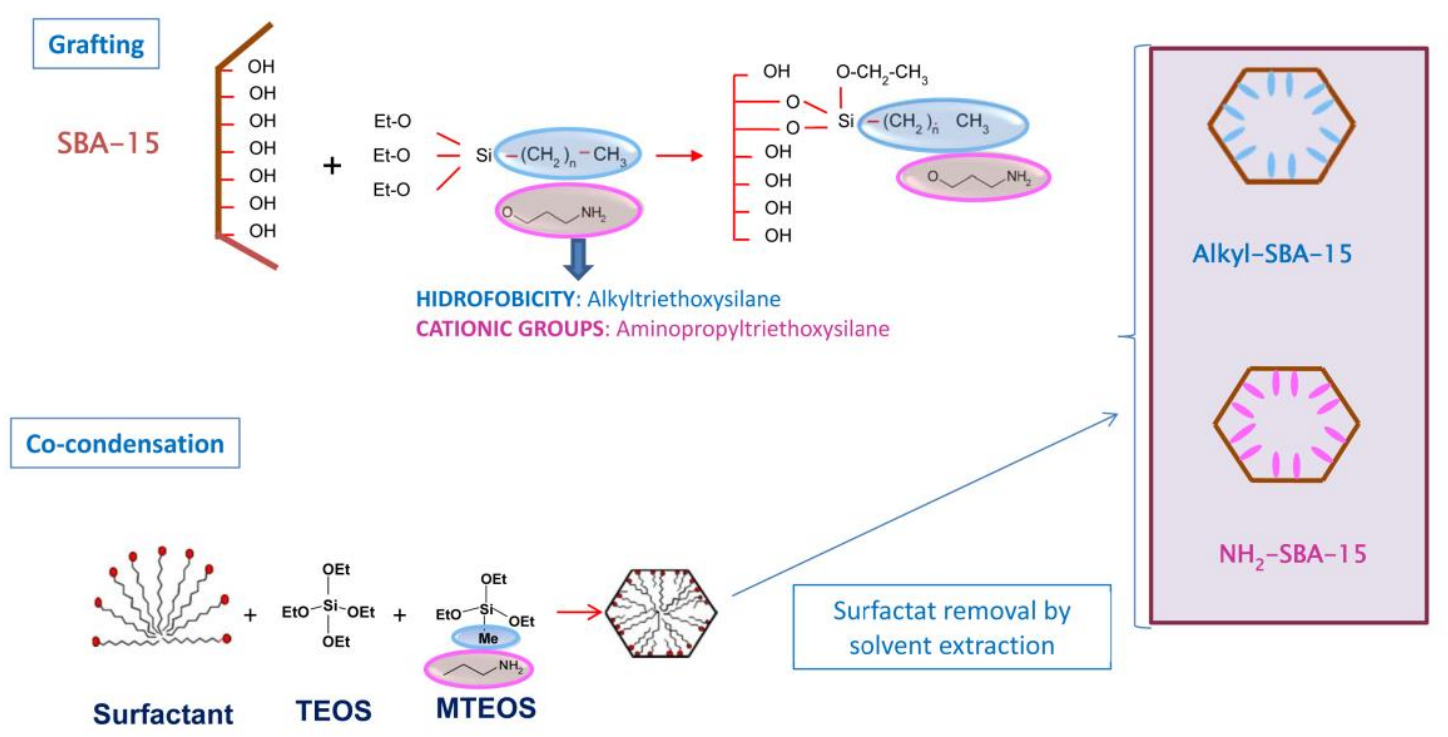

Figure 4. Two routes commonly employed in the functionalization of the pore surface of Ordered Mesoporous Materials.

A third functionalization method in OMM should be described to further understand the designing capacity. Periodic Mesoporous Organosilicas (PMO) were introduced in the OMM community in 1999 [25] as a hybrid version of OMM in which a variety of organosilica sources are actually forming the pore walls, leading to very hydrophobic and very reactive pore walls [26]. These PMO are synthesized using 100\% organo-disilanes 
that assemble around the surfactant micelles in a very weak manner via van der Waals forces. There are less $\mathrm{OH}$ groups remaining on the pore surface since all the framework is built up from organic groups bridging $-\mathrm{Si}-(\mathrm{O}-\mathrm{Si}-)_{3}$ moieties. A more recent version of PMO is known as PMA (from Periodic Mesoporous Aminosilicas), in which the same approach is used to introduce amino groups on the pore walls following the scheme in Figure 5 [27]. The synthesis conditions can be slightly altered to obtain larger pores in which the two functionalities can be accommodated while producing large pores.

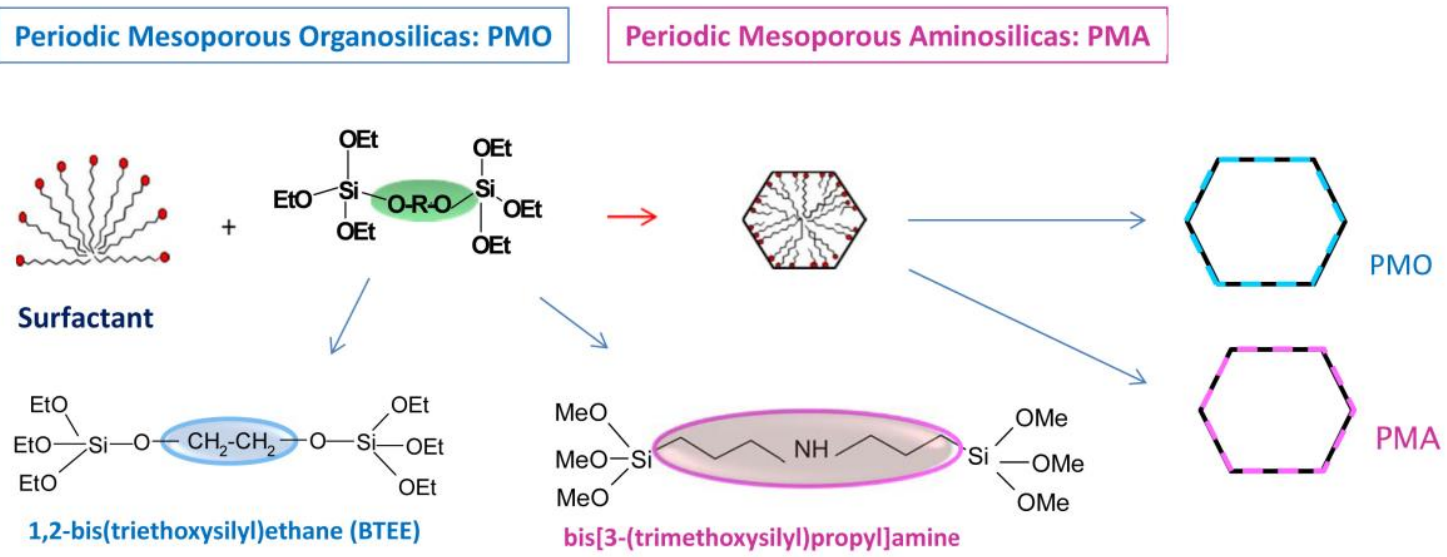

Figure 5. General synthesis scheme of Periodic Mesoporous Organosilicas.

In summary, depending on the enzyme to be used, the functional groups could be selected, and thus the functionalization method should be designed.

As it has been mentioned before, the properties to be exploited from these supports include surface area and pore architecture along with the functionalities. These properties will be discussed and evaluated using $\mathrm{N}_{2}$ adsorption/desorption isotherms results as an evidence of the adequate initial textural properties of the supports and how the pore volume decreases upon enzyme loading. Thermogravimetry, chemical analysis and solid state NMR enable the identification and quantification of the functionalities. Scanning electron microscopy (SEM) will be used to evaluate de OMM particle size and morphology in the cases where we aim to control the particle growth to facilitate the enzyme diffusion. Conventional transmission electron microscopy (TEM) allows identifying the pore architecture. However, given the low scattering power of C-based materials, it remains a challenge to locate the presence of enzymes inside the pores after immobilization. In this regard, we have devoted efforts to analyze the materials using 
advanced electron microscopy techniques such as scanning transmission electron microscopy (STEM) combined with a high-angle annular dark field (HAADF) detector because the contrast is related to the atomic number $\mathrm{Z}$. With the modern electron microscopes, which incorporate spherical aberration (Cs) correctors, probes down to subAngstrom resolution can be achieved, which facilitates an exhaustive analysis of the pores of the OMMs which, combined with electron energy loss spectroscopy (EELS), allows the location of the enzymes inside the pores [28-30].

A high and permanent activity per unit weight or volume of the biocatalyst is the goal to achieve when designing the enzyme-support system of immobilization. The support must provide high surface area available for a high amount of protein molecules. This surface must contain residual groups to interact with side groups of the amino acids of the protein, either via covalent bonding or non-covalent interactions. The use of ordered mesoporous materials fulfils most requirements for an ideal enzyme-support system. To the high surface area, these materials add the uniform structure of the porous network and tuneable size and shape of the pores. Pores with size just a few nanometers larger than enzyme dimensions permit enzyme diffusion across them.

By covalent attachment, the enzyme is permanently linked to the support, i.e., no leaching happens. But enzyme molecules bonded at the edges of the pore would act as a stopper preventing access of new molecules and decreasing enzyme loading, so non-covalent interaction is preferred for immobilization of enzymes on OMM. Another drawback of covalent bonding is that it requires chemical modification of the protein, often leading to activity loss, and the impossibility to reuse the support after enzyme inactivation. Noncovalent link of the enzyme in OMM does not require chemical modification of the protein, and the support can be reused after enzyme inactivation [31]. Exploiting the confined mesoporous space of OMM allows developing biocatalysts where a close match between sizes of enzyme and pore creates a system where leaching is prevented and activity is preserved. Additionally, the narrow and uniform pores of OMM contribute to prevent the immobilization of enzyme aggregates and provide connectivity to favour a good diffusion of substrate and products.

Prior to describe enzyme-support immobilization systems with OMM, the parameters to improve in the biocatalysts are listed and described. 
The catalysts are defined by:

Enzyme loading: miligrams of enzyme immobilized per gram of the siliceous material

Time of immobilization: the time needed to complete the enzyme immobilization, i.e., when the activity of the supernatant is zero or decreases to a constant value.

Catalytic activity: Units of enzyme activity per gram of final catalyst (immobilized enzyme). A unit of enzyme activity is defined as the micromoles of substrate transformed by the enzyme per minute.

Specific activity (also called catalytic efficiency): The ratio between catalytic activity and enzyme loading, this is, the units of activity per milligram of immobilized enzyme. This is a crucial parameter that serves to compare different catalysts (regardless of the enzyme loading of them) and indicates the activity preserved by the enzyme upon immobilization. Specific activity is the best way to know how efficient the immobilization system is.

\subsection{Hydrophobic porous supports for lipase immobilization}

Lipases are glyceryl hydrolases: these enzymes catalyze the hydrolysis of ester bonds, particularly between glycerol and fatty acids. This family of enzymes has as common feature the presence of a hydrophobic domain on the surface which becomes part of their regulation mechanism in living beings. These hydrophobic amino acids interact among them acting as a lid which is closed in aqueous medium preventing the access of substrates to the active centre. In the presence of hydrophobic interfaces a conformational change occurs and the lid opens. This is known as interfacial activation [32]. These amino acids establish new interactions with the hydrophobic interface, which gives access to the active centre. This phenomenon has been profusely exploited for the immobilization of lipases on hydrophobic surfaces of support materials. The particular enzyme of this case is Lipase from Candida antarctica $\mathrm{B}$, with a molecular weight of $35 \mathrm{KDa}$, and approximate molecular dimensions of $3 \mathrm{~nm} \times 4 \mathrm{~nm} \times 5 \mathrm{~nm}$. Although this enzyme lacks the lid, it has a hydrophobic domain on its surface. Siliceous OMM and functionalized OMM whose surfaces were chemically modified with alkyl groups were obtained to study how the size 
and shape of the pores may affect the parameters related to enzyme immobilization, namely enzyme loading, activity, leaching and stabilization of the enzyme [33].

Two purely siliceous supports with channel-like pore structure were obtained: SBA-15, with parallel cylindrical pores in a 2D hexagonal arrangement, and KIT-6, which has two sets of interweaving, non-intersecting channels in a bicontinuous cubic symmetry (see Figure 3). Provided the width of the channels, functionalization was performed with methyl groups to prevent the pore diameter from an excessive decrease. Methylation via co-condensation with methyltriethoxysilane produced the respective functionalized materials bearing pendant methyl groups (see Figure 4): Me-SBA-15 and Me-KIT-6. PMO, a hybrid organosilica with 2D hexagonal arrangement of parallel cylindrical pores, was synthetized as described above (see Figure 5), containing bridging ethylene groups as part of the surface of the pores.

The textural properties of the supports are collected in Table 1 along with the immobilization results. The obtained pore sizes seem to be large enough for the dimensions of CaLB. However, enzyme loading in purely siliceous materials only reached moderate values which were not surpassed by the corresponding methylated counterparts. The mild hydrophobicity provided by methyl groups does not seem to be enough to compensate the decrease in pore diameter when alkyl groups are anchored. The enzyme loading increased in PMO, where ethylene groups are in higher amount than methyl ones on Me-SBA-15 and Me-KIT-6 [34].

Table 1. Textural properties of supports, enzyme adsorption time and loading, and activity of immobilized lipase in tributyrin hydrolysis.

\begin{tabular}{|ccccccc|}
\hline Material & $\begin{array}{c}\text { Pd } \\
\mathbf{n m}\end{array}$ & $\begin{array}{c}\mathbf{S}_{\text {BET }} \\
\mathbf{m}^{\mathbf{2}} \mathbf{g}\end{array}$ & $\begin{array}{c}\mathbf{t} \\
\mathbf{m i n}\end{array}$ & $\begin{array}{c}\text { Enz Load } \\
\mathbf{m g} / \mathbf{g}\end{array}$ & $\begin{array}{c}\text { Cat Act } \\
\mathbf{U} / \mathbf{g}\end{array}$ & $\begin{array}{c}\text { Specif } \\
\text { Act U/mg }\end{array}$ \\
\hline SBA-15 & 8.8 & 890 & 120 & 44 & 2.647 & 60 \\
\hline Me-SBA-15 & 7.9 & 794 & 200 & 23 & 2.009 & 88 \\
\hline KIT-6 & 8.4 & 917 & 280 & 37 & 2.442 & 66 \\
\hline Me-KIT-6 & 7.7 & 984 & 50 & 35 & 2.884 & 82 \\
\hline PMO & 7.1 & 960 & 60 & 91 & 18.280 & 202 \\
\hline AS & 27.9 & 305 & 120 & 45 & 4.552 & 100 \\
\hline OAS & 23.6 & 294 & 60 & 200 & 13.000 & 83 \\
\hline
\end{tabular}

Free enzyme activity: $533 \mathrm{U} / \mathrm{mg}$ 
Transmission electron microscopy studies allowed revealing the porous structure, along with scanning electron microscopy that showed the morphology of the materials. Figure $6 \mathrm{a}$ and $6 \mathrm{~b}$ show the rod like morphology of Me-SBA-15 (SBA-15-L in Figure 6) and the hexagonal arrangement of channels along the axis of the rods.

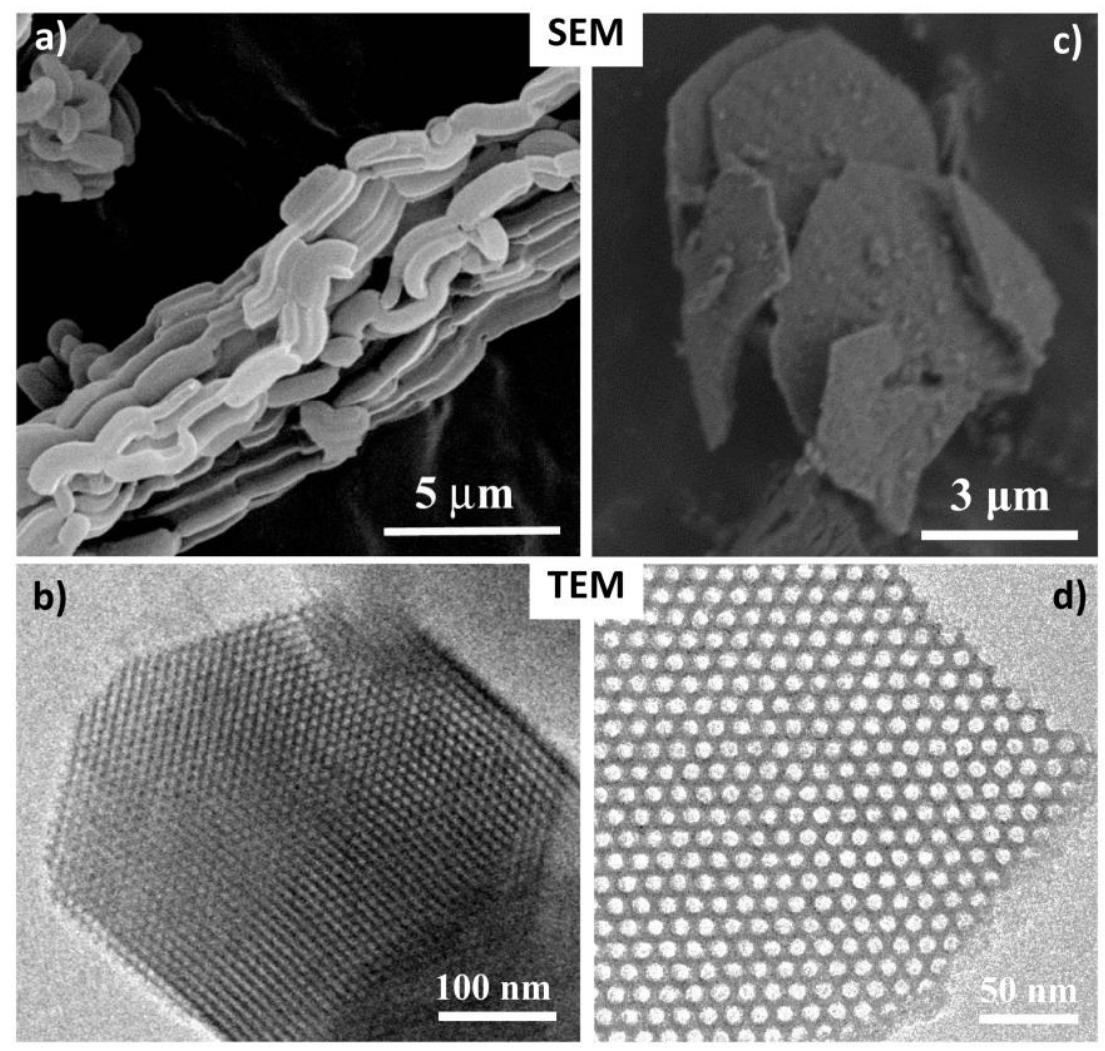

Figure 6. Scanning (SEM) and Transmission (TEM) Electron Microscopy of SBA-15 prepared under different synthesis conditions obtaining long (SBA-15-L) and short (SBA15-S) channels.

Diffusion in such long fibres is predictable to be difficult. However, in the case of PMO, despite the presence of similar crystal morphology (Figure 7a), the higher hydrophobicity of the pore walls seems to be the driving force for the lipase to diffuse in and load the channels. Advanced electron microscopy techniques allowed in this case identifying the lipase macromolecules inside the channels of the hexagonal PMO structure. Figure $7 \mathrm{~b}$ shows a Cs-STEM image in which the carbon contrast is not observed due to its weak scattering power even though using the Z-contrast mode, i.e., High Angular Annular Dark Field Detector (HAADF). However, the careful exposure of the area to the electron beam, controlling the electron dose and voltage, allowed obtaining Electron Energy Loss Spectra (EELS) of a small area depicted in the inset of the image. Figure 7c shows a small 
region in which the red areas are those with higher $\mathrm{C}$ content. At the same time, it is possible to confirm that the centre of a pore (in red) corresponds to the loading of the lipase by punctual EEL spectra (Figure 7d).
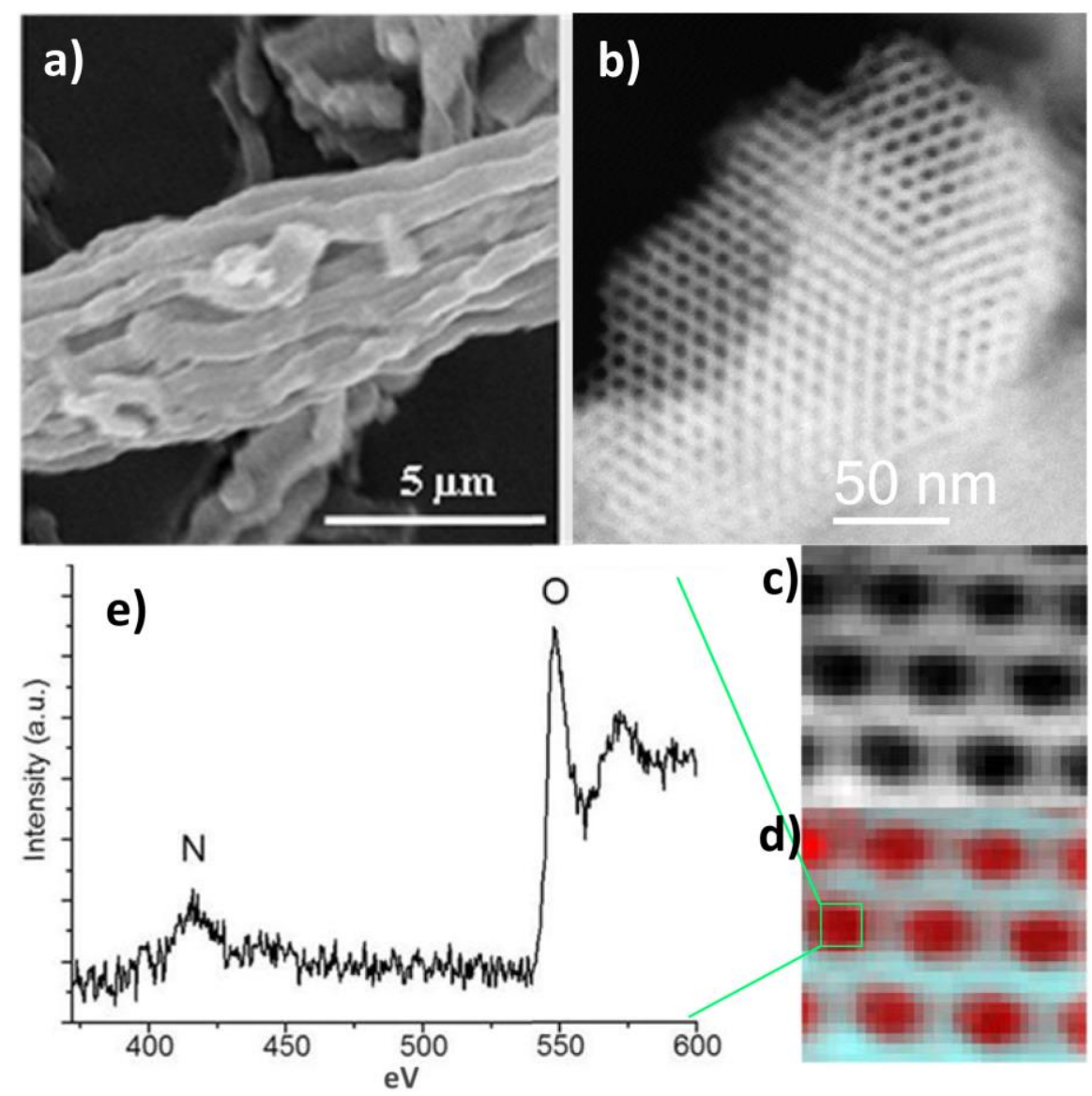

Figure 7. a) Morphology of PMO particles observed by SEM; b) Cs corrected STEMHAADF image of Lipase/PMO; c) Cs corrected STEM-HAADF image of interest d) Image in which red areas correspond to higher content of carbon; e) Extracted EELS signals from the inner area of the channels indicate that the areas with high content in $\mathrm{C}$ also contain $\mathrm{N}$, which therefore corresponds to the enzyme molecules.

Enzyme leaching was also related to both, shape and chemical surface of the pores. Purely siliceous surface failed to retain enzyme in the straight, parallel, cylindrical pores, but it succeeded in siliceous KIT-6 because of the tortuosity of the pore network in this material (Figure 8). Materials containing hydrophobic organic moieties were efficient to prevent enzyme leaching in both pore structures. In all these cases an initial fast protein release was detected during the leaching tests, attributed to molecules immobilized on external surfaces of the particles or at the external edges of the pores, less protected by the 
confinement provided by the pores. After this, the enzyme remained within pores of methylated SBA-15 and KIT-6, as well as in PMO.

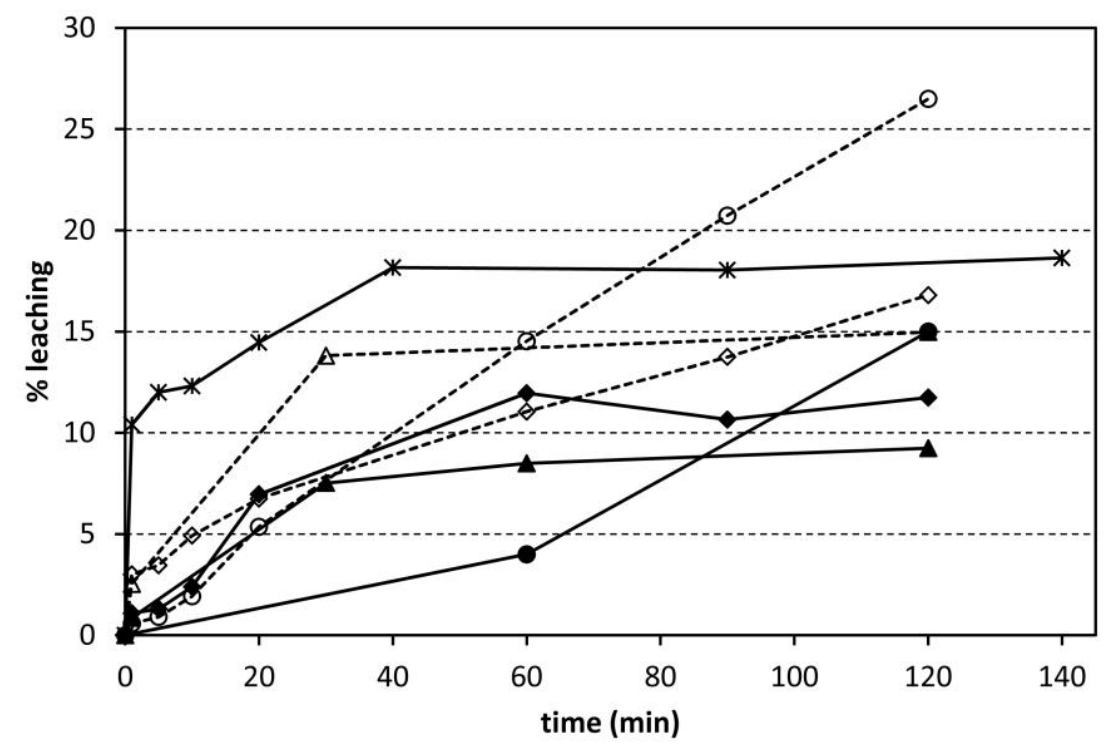

Figure 8. Leaching courses of lipase from OMM (channel pores) and amorphous silica materials, both in purely siliceous form and functionalized with hydrophobic groups. Empty rhombus: SBA-15. Filled rhombus: Me-SBA-15. Empty triangles: KIT-6. Filled triangles: Me-KIT-6. Empty circles: Amorphous silica. Filled circles: Octyl-Amorphous silica. Asterisk: PMO.

Since enzyme loading is different in each case, the activity of the catalysts is compared in terms of specific activity (i.e, per miligam of immobilized lipase). The activity was better preserved in the catalysts with methylated surfaces than in siliceous ones, in similar amounts (see Table 1). PMO-lipase also retained more activity with values of catalytic activity and specific activity significantly higher than all others. So with the same type of pores, the higher hydrophobicity of PMO enabled to improve the catalyst obtained compared to Me-SBA-15 [35].Cage-like structures were evaluated as an alternative to retain the enzymes in cages that provide with bigger space which would turn into more activity as it will have more free space to move and adjust its conformation to the reaction states. The idea was to provide some degree of hydrophobicity likewise in the channellike materials. We prepared Me-SBA-16 via co-condensation method, although we failed in preparing cage-like PMO type of materials. Instead, for this approach we also tackled a more delicate synthesis method that implied a ship-in-a-bottle scheme. The enzyme was used together with the surfactant as structure directing agent of a cage-like hybrid material as indicated in the top part of Figure 9. This sample is called "in-situ". We succeeded in 
finding the optimum synthesis conditions that allowed forming a combined micelle Lipase-surfactant while maintaining the activity of the enzyme. Furthermore, we managed to conduct the polymerization of the silica at $\mathrm{pH} 3.5$ yielding a cage-like OMM [20] and further elimination of the surfactant finally allowed obtaining the encapsulated hybrid biocatalyst. Table 2 collects the parameters corresponding to these cage-like samples. Figure 10 includes the SEM and TEM characterization of Me-SBA-16 that allowed the 3D reconstruction using Mathematica software, as a result the sizes of pore widows and cages could be accurately calculated as indicated in Table 2 . For the "in situ" sample, it was possible to characterize the ordered mesoporous structure; furthermore, advanced electron microscopy techniques allowed the location of the lipase in the cages [28]. The lower part of Figure 9 shows a spectrum image and spectrum profile analysis performed on the [100] orientation of in situ-lipase-SBA-12.
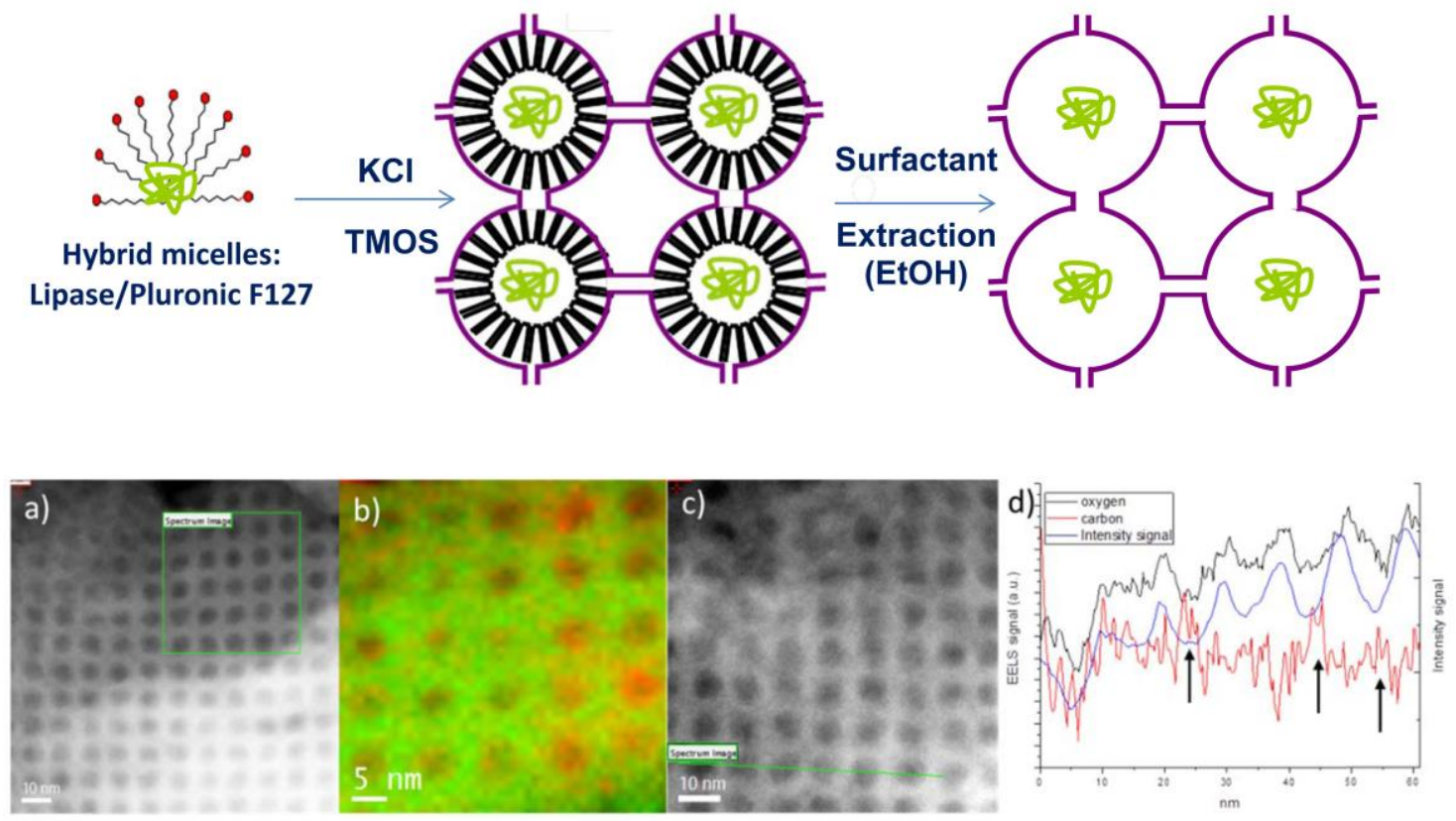

Figure 9. Synthesis scheme for the preparation of "in situ" Lipase/SBA-12, a cage like OMM. In the lower part of the Figure: a) Cs corrected STEM-HAADF, where the area of interest is marked by a green square. b) Spectrum image extracted by the carbon (in red) and oxygen (green) signals. c) Cs corrected STEM-HAADF image with the spectrum profile marked as a green line. d) Extracted signals from the line profile: in blue the intensity signal, in red the carbon and in black the oxygen. The arrows indicate that the valleys in the blue and black lines, corresponding to the channels, match with the peaks in the red line indicating the presence of carbon filling the pores. 


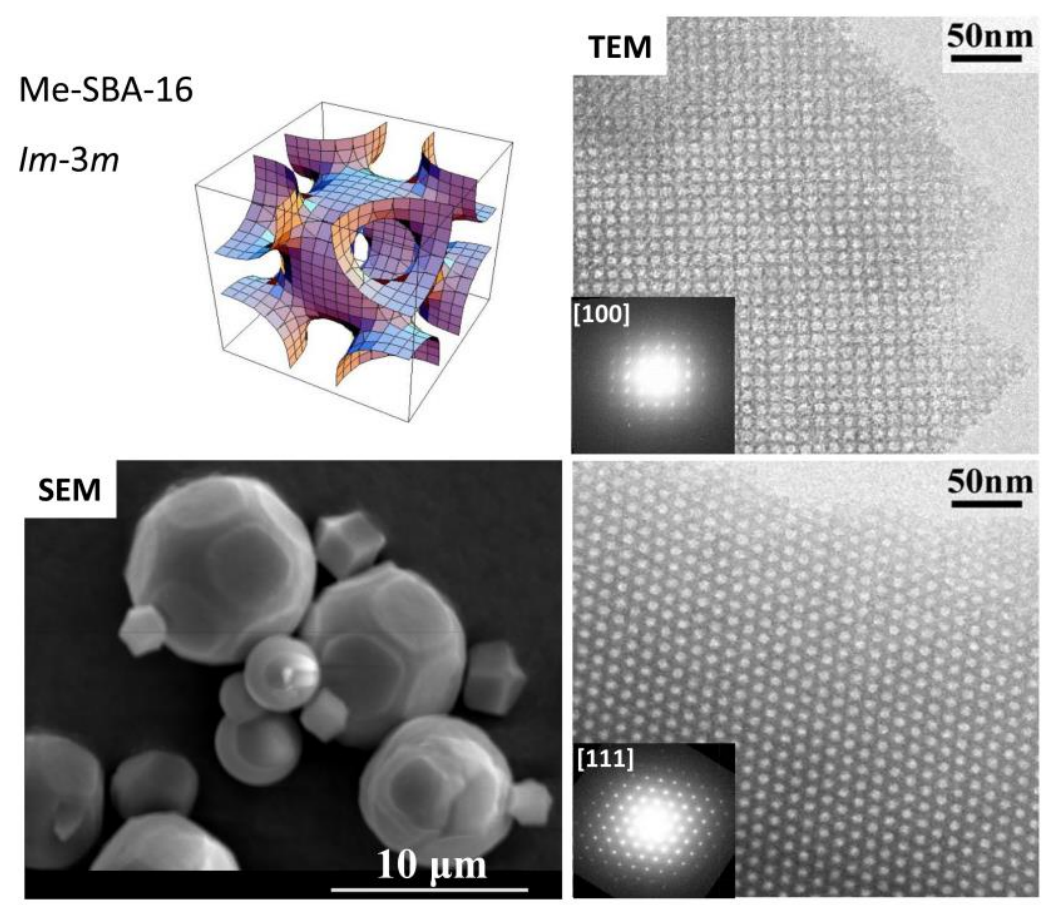

Figure 10. Me-SBA-16 structure 3D reconstruction based on the TEM results included as [100] and [111] zone axis, and SEM micrograph showing the faceted rounded particles.

In the case of Me-SBA-16, the immobilization is handicapped by the restricted access of enzyme across the narrow windows, as indicated by the long incubation times required and the low enzyme loadings achieved (Table 2), even in methylated materials. But, for the same reason, the enzyme release is also hindered and leaching profiles show saturation-like shapes (Figure 11).

If the materials are synthetized in the presence of the enzyme ("in situ" sample), the enzyme loading increases while the leaching remains prevented [20]. The activity retained by the enzyme is higher than the values displayed by all the catalysts prepared through post-synthesis immobilization (with both pore structures: channel and cages).

Table 2. Textural properties of supports, enzyme loading and activity of immobilized lipase in tributyrin hydrolysis.

\begin{tabular}{|cc|ccc|}
\hline Material & $\begin{array}{c}\text { Pd } \\
\mathbf{n m}\end{array}$ & $\begin{array}{c}\text { Pd-3DR } \\
\mathbf{n m}\end{array}$ & $\begin{array}{c}\text { Enz Load } \\
\mathbf{m g} / \mathbf{g}\end{array}$ & $\begin{array}{c}\text { Specif Act } \\
\mathbf{U} / \mathbf{m g}\end{array}$ \\
\hline SBA-16 & 10.2 & $12.3(4.6)$ & 5 & 72.4 \\
\hline Me-SBA-16 & 8.8 & $13.1(5.9)$ & 30 & 76.7 \\
\hline In situ & & & 93 & 108 \\
\hline
\end{tabular}




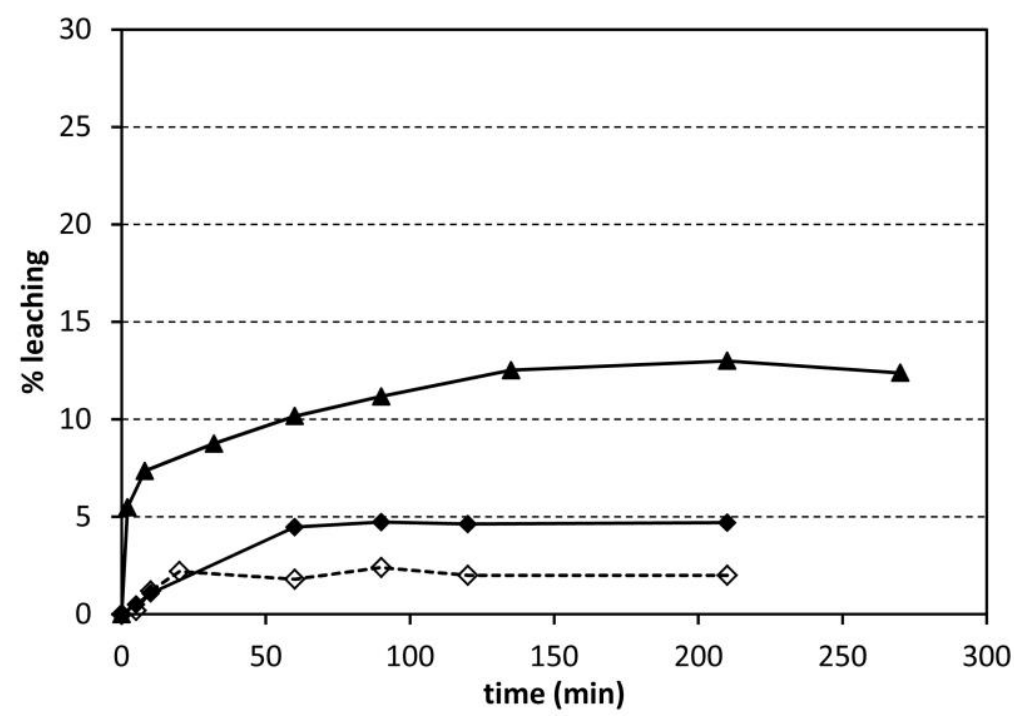

Figure 11. Leaching courses of lipase from the OMM (cage-window pores), both in purely siliceous form and functionalized with hydrophobic groups. Empty rhombus: SBA-16. Filled rhombus: Me-SBA-16.

\subsection{Amino-functionalized porous supports for laccase immobilization}

Laccases are a group of multicopper enzymes of industrial interest that catalyze the oxidation of phenolic compounds such as ortho- and para-diphenols to their corresponding quinones with the concomitant reduction of oxygen to water [36, 37]. The laccase used, from M. thermophila expressed in A. oryzae, has a low isoelectric point ( $\mathrm{pI}$ around 4) and a molecular weight of around $89 \mathrm{kDa}$, with enzyme dimensions of approximately $6.1 \mathrm{~nm} \times 5.0 \mathrm{~nm} \times 4.9 \mathrm{~nm}$. [38]. Having in mind these features, to carry out enzyme adsorption at $\mathrm{pH}$ values close to neutrality, the support material should contain positive charges in order to establish electrostatic interactions with the enzyme $[10,39]$. Therefore, functionalization of the siliceous supports was carried out with high pKa groups (amine) using aminopropyltriethoxysilane as precursor. In this case, it is important to notice that pore size can be significantly decreased when the support is functionalized with a large reagent as aminopropyltriethoxysilane, which should be taken into account when designing the appropriate mesoporous support according to the dimensions of this enzyme.

Immobilization on purely siliceous materials was studied first, through the synthesis of SBA-15 via two different strategies yielding different particle morphology as shown in 
Figure 6: an SBA-15 sample with conventional rod type of particles, showing long channels (SBA-15-L) running parallel to the rod axis, and a second one grown as thin hexagonal plates containing shorter mesochannels aligned parallel to the short axis of the dishes (SBA-15-S) [40]. Despite the smaller pore diameter and lower surface area of SBA-15-S, its shorter channels (of about $170 \mathrm{~nm}$ length) can accommodate more enzyme molecules per unit length than the longer ones of SBA-15-L (1000 nm length) where a part of the inner surface of the channel is not accessible to laccase molecules. Regarding specific activity, the lower value obtained for SBA-15-L indicates that the longer channels seem to hamper the diffusion of substrates and products more than the shorter ones (Figure 12).

A

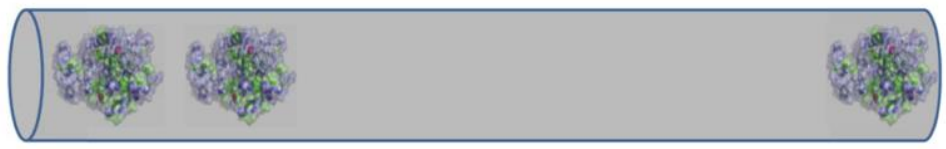

$1000 \mathrm{~nm}$

B

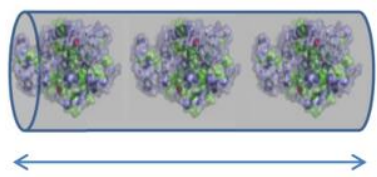

$170 \mathrm{~nm}$

Figure 12. Schematic illustration of laccase immobilization on SBA-15-L mesochannels (a) and SBA-15-S mesochannels (b).

PMA, or Periodic Mesoporous Aminosilica, was synthetized using bis[(3trimethoxysilyl)propyl]amine and 1,2-bis(trimethoxysilyl)ethane as framework coprecursors following the scheme in Figure 5. Instead of being anchored to the pore surface as pendant groups, the amine groups in this material are integrated within the hibrid organosiliceous framework, and thus they do not contribute to decrease the pore diameter but are part of the pore surface itself. However, the enzyme loading achieved does not significantly increase compared to the purely siliceous SBA-15 materials as indicated in Table 3. These results suggested that adsorption of laccase in these supports might be 
Table 3. Textural properties of silica and hybrid amino-silica supports, enzyme loading and activity of immobilized laccase in ABTS oxidation.

\begin{tabular}{|ccccccc|} 
Material & $\begin{array}{c}\text { Dp } \\
\mathbf{n m}\end{array}$ & $\begin{array}{c}\text { SBET } \\
\mathbf{m}^{\mathbf{2}} / \mathbf{g}\end{array}$ & $\begin{array}{c}\mathbf{P v} \\
\mathbf{c m}^{\mathbf{3}} / \mathbf{g}\end{array}$ & $\begin{array}{c}\text { Channel } \\
\text { length } \mathbf{~ n m}\end{array}$ & $\begin{array}{c}\text { Enz load } \\
\mathbf{~ m g / g}\end{array}$ & $\begin{array}{c}\text { Specif act } \\
\text { U/mg }\end{array}$ \\
\hline SBA-15-L & 7.8 & 609 & 1 & 1000 & 31.28 & 0.134 \\
\hline SBA-15-S & 6.4 & 550 & 0.7 & 170 & 38.41 & 0.159 \\
\hline PMA & 7.2 & 594 & 0.7 & - & 42 & 0.11 \\
\hline
\end{tabular}

restricted due to the presence of too narrow pores. It seemed therefore necessary to synthesize supports with wider pore diameters.

A micelle expander was used in the synthesis of SBA-15 and PMA to obtain supports with wider pores following the general synthesis approach described in Figure 3 as well as Figure 5. Thus, wide-pore silica SBA-15 and hybrid aminosilica PMA (sample EPMA) were obtained using triisopropylbenzene (TIPB) as swelling agent. Wide-pore SBA-15 silica was grafted with APTES for functionalization with amino groups (sample NGOES). Also, a wide-pore aminopropyl-SBA-15 support was obtained by a one-step method via co-condensation of TEOS and APTES (Figure 4) in the presence of the nonionic surfactant and the swelling agent (sample NCOES). The textural properties and nitrogen content of these supports are reported in Table 4, along with the enzyme loading and activity of the biocatalysts obtained by adsorption of laccase on them.

Enzyme loading increased significantly in expanded SBA-15 materials containing amine groups and E-PMA compared to the supports with narrower pores. The enzyme loading achieved in the mesoporous materials seems to be directly related to the nitrogen content in each one of them. Actually, the catalytic efficiency is very similar for the three samples [41]. An amorphous silica (AS) functionalized with APTES (sample NAS) used for comparison also followed this trend: higher laccase loading and higher $\mathrm{N}$ content. In this

Table 4. Textural properties of supports, nitrogen content (amino groups), enzyme loading and activity of immobilized laccase in ABTS oxidation.

\begin{tabular}{|cccccccc|}
\hline Material & $\begin{array}{c}\mathbf{D p} \\
\mathbf{n m}\end{array}$ & $\begin{array}{c}\mathbf{P v} \\
\mathbf{c m}^{\mathbf{3}} / \mathbf{g}\end{array}$ & $\begin{array}{c}\text { SBET } \\
\mathbf{m}^{\mathbf{2}} / \mathbf{g}\end{array}$ & $\begin{array}{c}\mathbf{N} \text { content } \\
\mathbf{m m o l} / \mathbf{g S i O}\end{array}$ & $\begin{array}{c}\text { Enz load } \\
\mathbf{m g} / \mathbf{g}\end{array}$ & $\begin{array}{c}\text { Cat Act } \\
\mathbf{U} / \mathbf{g}\end{array}$ & $\begin{array}{c}\text { Specif Act } \\
\mathbf{U} / \mathbf{m g}\end{array}$ \\
\hline NGOES & 11.2 & 1.0 & 339 & 1.2 & 170 & 50.7 & 0.30 \\
\hline NCOES & 17.6 & 1.2 & 385 & 1.5 & 174 & 56 & 0.32 \\
\hline E-PMA & 10.4 & 0.6 & 264 & 1 & 88 & 29 & 0.33 \\
\hline AS & & 2.5 & 296 & - & 16 & 0.52 & 0.03 \\
\hline NAS & & 2.1 & 236 & 1.8 & 187 & 169.5 & 0.91 \\
\hline
\end{tabular}


case also the catalytic efficiency was higher. However, the enzyme leaching profiles repeated the same pattern as the lipase catalysts (Figure 13).

Similarly to the lipase in PMO, this study reveals that the close environment provided by the E-PMA material yields a maximum catalytic efficiency of the immobilized laccase. In this sample, we tried to locate and identify the presence of the laccase inside the channels using advanced transmission electron microscopy techniques. The highly regular porosity of the support achieved using micellar expanders was confirmed by the Cs corrected STEM-HAADF images (Figure 14a). A selected region of the sample (green square in Figure 14a) was further analysed yielding the N-mapping (Figure 14b). In this case, chemical analysis by EELS indicated that nitrogen was evenly distributed within the framework that forms the pore walls. As shown in Figure 14b, nitrogen was also detected inside most of the pores, which could be attributed to adsorbed laccase molecules. However, the low scattering power of C-based molecules such as enzymes yields no contrast at all inside the pore spaces of the Cs corrected STEM-HAADF images (Figure $14 \mathrm{a}$ and $\mathrm{c}$ ), which obstructs the direct observation of the protein molecules inside the pore channels. Nevertheless, the punctual analysis in the centre of a channel (marked in Figure 14c) allows observing the $\mathrm{C}, \mathrm{N}$ and $\mathrm{O}$ edges in the EELS profiles, corroborating the location of the laccase molecules.

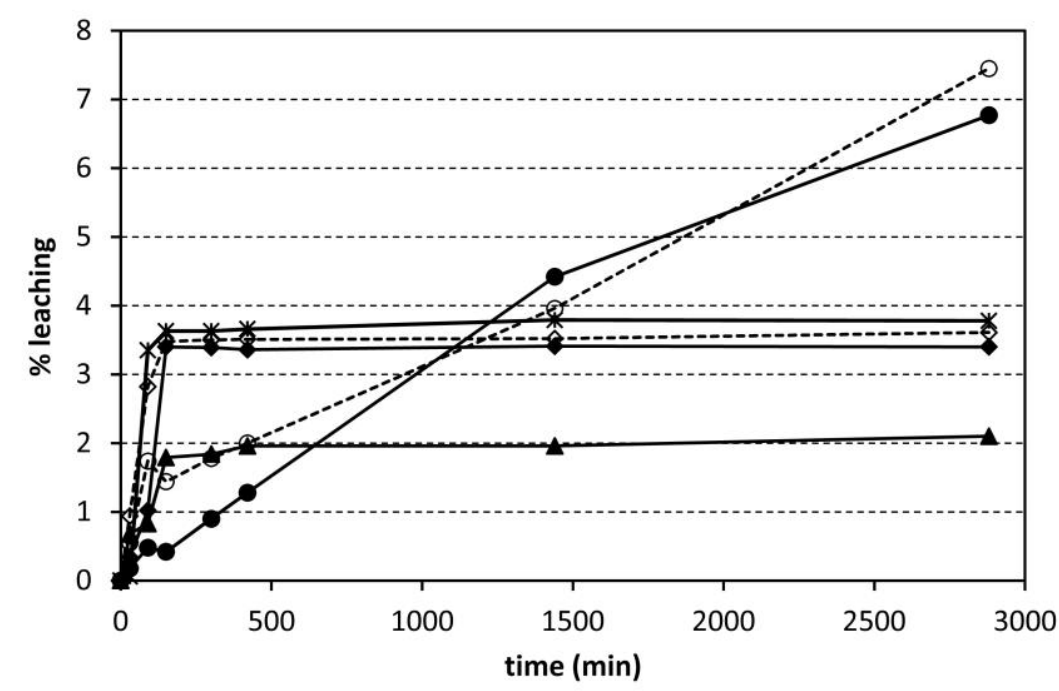

Figure 13. Leaching courses of laccase from the OMM purely siliceous and functionalized with amine groups. Empty rhombus: OES. Filled rhombus: NGOES. Triangles: NCOES. Asterisks: PMA. Empty circles: Amorphous silica. Filled circles: PropylamineAmorphous silica. 


\subsection{MOF as platforms to support enzymes}

Among the numerous potential applications of MOF materials, their use as supports for enzyme immobilization resulted evident due to their extraordinary compositional versatility and their porous nature. Obviously the most direct approach was to search MOF materials having pores large enough to encapsulate enzymes [42, 43]. Unfortunately just a few MOF materials possess so big pores. In addition, such MOF materials are generally unstable and very hard and expensive to be prepared. More importantly, even these scarce large-pore-containing MOF materials can only host a limited number of enzymes.

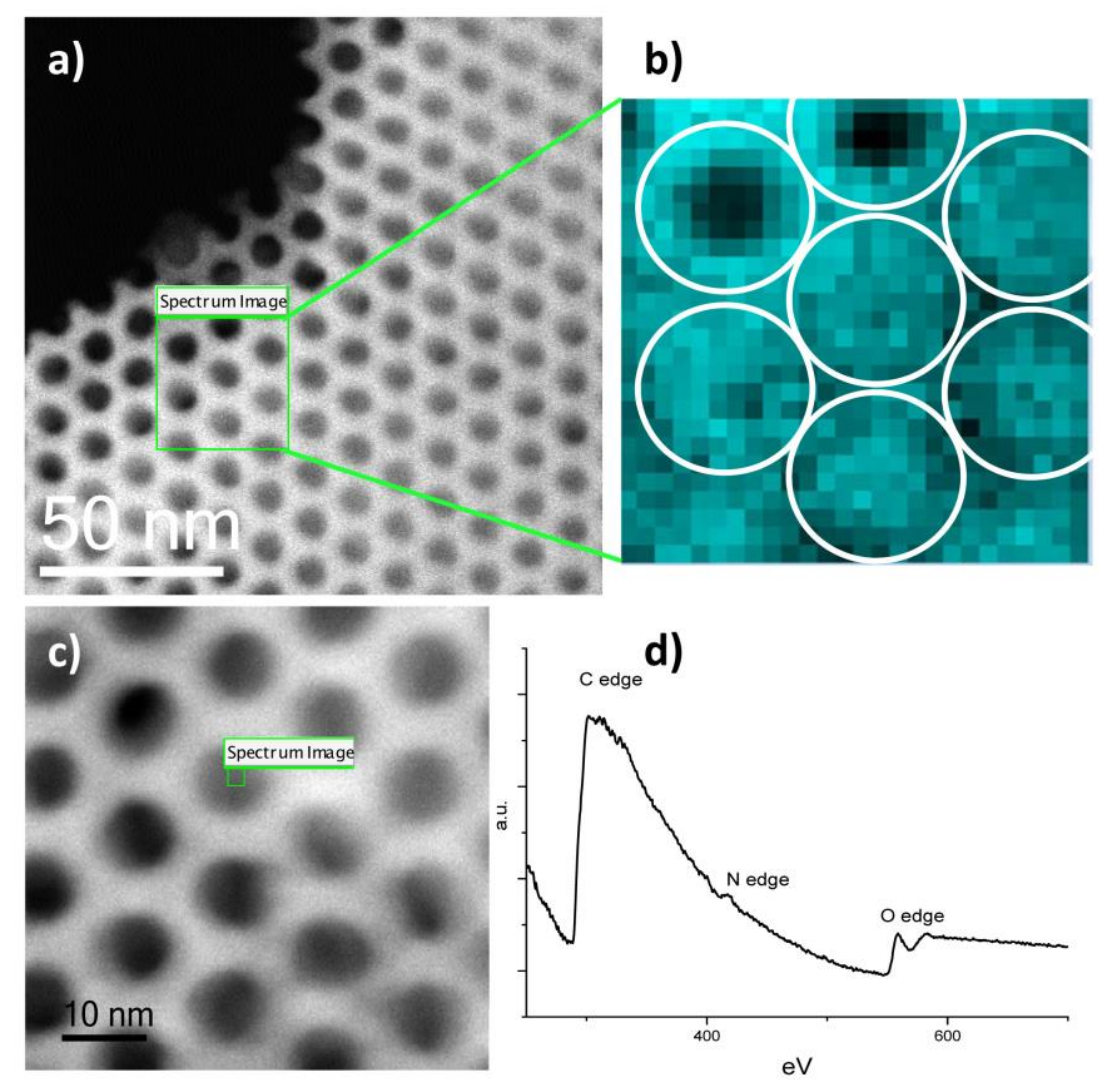

Figure 14. a) Cs corrected STEM-HAADF image of Laccase/E-PMA; b) Image in which blue areas correspond to higher content of Nitrogen; c) Cs corrected STEM-HAADF image of interest; d) Extracted EELS signals from the inner area of the channels indicating that the high content in $\mathrm{N}$ is associated with $\mathrm{C}$ and $\mathrm{O}$, which therefore corresponds to the enzyme molecules. 
In the very last years, these drawbacks have been solved by very different strategies, making practically universal the use of MOFs to support any enzyme. Some of the most innovative approaches are mentioned in this section. As a complement of the information given here, recent reviews covering in detail all described methodologies of enzyme immobilization on MOF materials can be found elsewhere [44-47].

The affinity between MOF materials and enzymes is so favored that the simple contact between both entities somehow generates the immobilization, although the kind of interaction is not described [48, 49]. The immobilization of enzymes on MOFs can also be achieved by in-situ strategies [50-52] taking advantage of the possibility of preparing MOF materials under soft conditions compatible with the bioactivity of enzymes. Depending on the followed in-situ strategy, enzymes can be finally embedded within the MOF crystal [50] or they can even become part of the MOF, acting as nodes (linkers) [51, 52]. The first strategy could find serious diffusion problems of reactants and/or products, as they must go through the pores of the MOF materials; indeed the enzymatic activity of the so prepared biocatalysts was only probed in the degradation of $\mathrm{H}_{2} \mathrm{O}_{2}$, which has no diffusion problems [50]. In the second strategy, the enzymatic immobilization implies the covalent union to the support, which sometimes affects negatively the catalytic activity of the immobilized enzyme.

Our group developed a new methodology to prepare MOF materials under very soft conditions, which include the use of water as unique solvent, room temperature preparation, the absence of any corrosive reactant and no energy input [53-56]. As an additional advantage, this method generally produces nanocrystalline MOF materials, whose crystals are aggregated/agglomerated describing more or less ordered intercrystalline mesoporosity. Not less importantly, the experimental conditions (temperature, synthesis time, $\mathrm{pH}$, etc.) under which the MOFs support are prepared, becomes friendly with the enzymatic activity. All this allows carrying out a systematic comparison between the in-situ and post-synthesis immobilization of enzymes on these nanocrystalline MOFs materials following the scheme plotted in Figure 15 [57, 58].

In-situ approaches generated solid biocatalysts with high enzyme loadings (at least $85 \%$ of the enzyme added to the synthesis media) and with lower enzyme leaching, whereas the intrinsic catalytic activity per enzyme molecule was higher in the post-synthesis 
biocatalysts. These results are in good agreement with the encapsulation of enzymes within the intercrystalline mesoporosity of the MOF materials [58]. The universality of this methodology was made clear by using different immobilization methodologies, different MOF supports, different enzymes and different synthesis media, including N,Ndimethylformamide, in which $\beta$-glucosidase immobilized on Mg-MOF-74 material kept certain activity for at least 24 hours whereas the free enzyme was inactivated in a few minutes $[57,58]$.
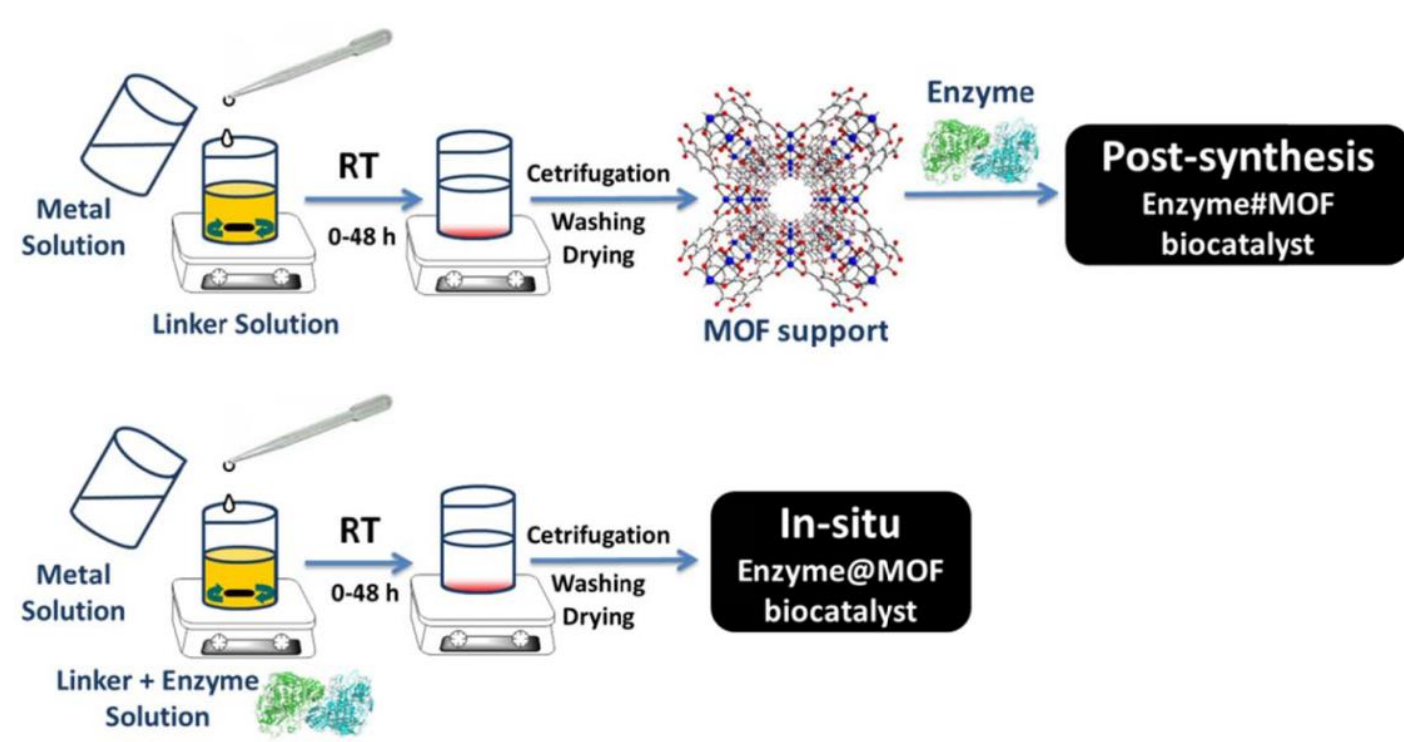

Figure 15. Visual diagram of the experimental procedures to prepare: (i) post-synthesis Enzyme\#MOF biocatalysts, at the top; and (ii) in-situ (one-step) Enzyme@MOF biocatalysts, at the bottom, developed by our group [57-59].

The method was particularly effective when the semi crystalline MOF material Fe-BTC (commercially known as Basolite F300) was the support. Such material, directly prepared by our group under sustainable conditions [55], efficiently immobilized the enzymes laccase, alcohol dehydrogenase, lipase, and glucose oxidase by in-situ procedure [59]. Table 5 shows the enzyme immobilization efficiency, the enzyme loading, and the enzymatic activity of different solid biocatalysts prepared by in-situ immobilization of the mentioned enzymes on the Fe-BTC MOF material. Regardless of the nature of the immobilized enzyme, the efficiency of the immobilization is higher than $95 \%$, except for the experiment carried out at high lipase content (71\%). Enzyme loadings become as high as $100 \mathrm{mg} / \mathrm{g}$ in the case of alcohol dehydrogenase. Moreover, the catalytic activity 
Table 5. Catalytic properties of the in-situ-prepared Enzyme@Fe-BTC biocatalysts in different reactions [59]. The activity of the solid biocatalysts is compared with that of the corresponding free enzymes.

\begin{tabular}{|ccccc|}
\hline Enzyme & $\begin{array}{c}\text { Immobilized } \\
\text { Enzyme }\end{array}$ & $\begin{array}{c}\text { Enz Load } \\
\text { mg/g }\end{array}$ & $\begin{array}{c}\text { Activity } \\
\text { U/g }\end{array}$ & $\begin{array}{c}\text { Specif Act }^{\mathbf{d}} \\
\mathbf{U} / \mathbf{m g}\end{array}$ \\
\hline Laccase $^{\mathbf{a}}$ & 99 & 19 & 751 & $39(378)$ \\
\hline \multirow{2}{*}{ Lipase B $^{\mathbf{b}}$} & 95 & 16.5 & 27.6 & $1.67(2.01)$ \\
\hline Glucose oxidase $^{\mathbf{a}}$ & 71 & 45.7 & 90.2 & $1.97(2.01)$ \\
\cline { 2 - 5 } & 100 & 1.1 & 3.6 & $3.40(1.40)$ \\
\hline Alcohol dehydrogenase $^{\mathbf{c}}$ & 100 & 2.9 & 4.5 & $1.59(1.40)$ \\
\cline { 2 - 5 } & 100 & 68.4 & 0.62 & $0.09(1.58)$ \\
\cline { 2 - 5 } & 100 & 99.6 & 0.51 & $0.01(1.58)$ \\
\hline
\end{tabular}

aTested reaction: Oxidation of the 2'azino-bis-(3-ethylbenzothiazoline-6-sulfonate) diammoniun salt (ABTS). ${ }^{b}$ Tested reaction: Hydrolysis of p-nitrophenyl acetate (p-NPA). ${ }^{c}$ Tested reaction: Oxidation of ethanol to acetaldehyde. ${ }^{\mathrm{d}}$ The values in brackets correspond to the activity of the free enzyme.

of the biocatalysts Enzyme@Fe-BTC is maintained at some extent, even overcoming (2.5 higher!) that of the free enzyme in the case of the glucose oxidase.

The value of the here-presented enzyme immobilization methods on MOFs supports goes beyond mere academic interest. Although the MOF supports are sometimes thought as expensive or hard-to-prepare materials, the materials used in these approaches utilized inexpensive chemicals, water as solvent and room-temperature. Moreover, the MOF materials can be considered as bioMOFs, as they are composed by metals biocompatible even with the ingestion by human being (such as $\mathrm{Fe}, \mathrm{Zn}$ or $\mathrm{Mg}$ ), which makes them good candidates for any application related to food industry, biomedicine, etc.

\subsection{How can regular structures improve catalysts properties?}

In order to study and compare the possible effects of a regular structure of the support, Lipase and Laccase were immobilized on a commercial amorphous silica, with average pore size close to $30 \mathrm{~nm}$, much wider than those obtained with all OMM studied. Despite the lower surface area of this material, enzyme loadings achieved were higher than those obtained with OMM, as can be seen in Tables 1 and 4. However, significant differences 
were found and serve to distinguish which features can be improved in the final catalyst via the regular structure of the solid matrix.

First of all, the confinement of the enzyme in pores with uniform size that closely match the size of the enzyme has a double effect. A first consequence is that enzyme leaching is prevented due to the joint effect of the confinement and the chemical affinity with the pore surfaces. In the leaching tests, after the initial release of enzyme discussed above, no more enzyme release was detected at long incubation times for enzymes immobilized on OMM. On the contrary, enzymes are not retained in the wide-pore amorphous material functionalized to provide its surface with the same chemical affinity with the respective enzyme. The second effect of confinement is to assure that the enzyme is immobilized in a dispersed form, i.e., with no aggregation of enzyme molecules because of the restricted pore space where only one molecule of enzyme can fit. Thus, no loses of activity can be due to immobilization of aggregates. Thirdly, the high pore connectivity provided by the uniform shape and distribution of the porous network in OMM favours the diffusion of substrates and products. This effect, added to the lack of enzyme aggregation contributes to obtain higher specific activities with regard to the amorphous silica, especially in the case of lipase. Table 1 shows the lipase loading on amorphous silica (200 mg lipase/g of Octyl-functionalized Amorphous Silica, OAS), with pores with wide average pore diameters where the enzyme loading is much higher than that obtained with OMM. However, the specific activity is less than half the one obtained with PMO.

Particle size and shape also play a fourth main role. Decreasing particle size contributes to reduce diffusional restrictions of substrates and products, and thus also to obtain better catalytic efficiencies, due to the shortening of the length of pores. Furthermore, especially when the diameter of the pores is very close to enzyme dimensions, diffusion of enzyme during immobilization by adsorption can be restricted, leading to lower enzyme loadings in supports with longer pore channels, as shown above for immobilization of laccase on SBA-15 silica.

In summary, the possibility to obtain regular mesoporous materials which can be tuned according to the requirements of each enzyme allows to study each of the effects on the catalysts separately, and to improve their properties.

Furthermore, the strong chemical affinity between MOFs and enzymes can be inferred by the high number of successful studies about the enzyme immobilization on these supports carried out in the last two years by different groups and using different approaches, none 
of them requiring MOFs with structural mesopores [48-52, 57-59]. After so short research time, it is evident that so many aspects (location of the enzymes, interaction enzymeMOF, scale up to industrial level, etc.) of these strategies must be further investigated, but MOFs should definitively be considered as enzyme supports for future applications.

References

[1] Braun, S.; Rappoport, S.; Zusman, R.; Avnir, D. Ottolenghi, M. Mater. Lett. 1990, $10,1-5$.

[2] Avnir, D.; Braun, S.; Lev, O.; Ottolenghi, M. Chem. Mater. 1994, 6, 1605-1614.

[3] Gorton, L. Electroanal. 1995, 7, 23-45.

[4] Lev, O.; Wu, Z.; Bharathi, S.; Glezer, V.; Modestov, A.; Gun, J.; Ravinovich, L.; Sampath, S. Chem. Mater. 1997, 9, 2345-2375.

[5] Gill, I.; Ballesteros, A. J. Am. Chem. Soc. 1998, 120, 8587-8598.

[6] Livage, J.; Coradin, T.; Roux, C. J. Phys.: Condens. Matter. 2001, 13, R673-R691.

[7] Nassif, N. Bouvet, O. Rager, M.N. Roux, C. Coradin, T. Livage, J. Nature Mater. 2002, $1,42-44$.

[8] J.D. Brennan, D. Benjamin, E. DiBattista, M.D. Gulcev. Chem. Mater. 2003, 15, $737-745$

[9] M.L. Ferrer, D. Levy, B. Gomez-Lor, M. Iglesias. J. Mol. Catal. B: Enzym. 2004, 27, 107-111.

[10] Yiu, H. P.; Wright, P. A. J. Mat.Chem. 2005, 15, 3690. 3700

[11] Hartmann, M. Chem. Mater. 2005, 17, 4577.

[12] Díaz, J. F.; Balkus Jr., K. J. J. Mol. Catal. B: Enzimatic 1996, 2, 115

[13] Zhou, Z.; Hartmann, M. Chem. Soc. Rev. 2013, 42, 3894-3912

[14] Corma, A.; Fornes, V.; Jordá, J.L.; Rey, F.; Fernández-Lafuente, R.; Guisan, J.M.; Mateo, C. Chem. Comun. 2001, 419-420.

[15] Corma, A.; Fornes, V.; Rey, F. Adv. Mater. 2002, 14, 71-74

[16] Dumitriu, E.; Secundo, F.; Patarin, J.; Fechete, I. J. Mol. Catal. B-Enzym. 2003, 22, 119-133.

[17] Kresge, C. T.; Leonowicz, M. E.; Roth, W. J.; Vartulli, J. C.; Beck, J. S.; Nature 1992, 359, 710-712. 
[18] Zhao, D.; Feng, J.; Huo, Q.; Melosh, N.; Fredrickson, G. H.; Chmelka, B. F.; Stucky, G. D. Science 1998, 279, 548.

[19] Wan, Y.; Zhao, D.; Chem. Rev. 107, 2007, 2821- 2860.

[20] Urrego, S.; Serra, E.; Alfredsson, V.; Blanco, R.M.; Díaz. I. Microporous Mesoporous Mater. 2010, 129, 173-178.

[21] Gaffney, D.; Cooney, J.; Magner, E. Top. Catal. 2012, 55, 1101-1106.

[22] Magner, E. Chem. Soc. Rev. 2013, 42, 6213-6222;

[23] Hartmann, M.; Kostrov, X. Chem. Soc. Rev., 2013, 42, 6277

[24] Wight, A. P.; Davis, M. E. Chem. Rev. 2002, 102, 3589-361.

[25] Hoffmann, F. Cornelius, M. Morell, J. Fröba, M. Angew. Chem. Int. Ed. 2006, 45, 3216-3251.

[26] Satoru Fujita and Shinji Inagaki, Chem. Mater. 2008, 20, 891-908.

[27] Shea, K. J.; Loy, D. A. Chem. Mater. 2001, 13, 3306-3319

[28] Mayoral, A. Blanco, R. M. Díaz, I. J. Mol. Catal. B-Enzym 2013, 90, 23-25.

[29] Mayoral, A. Arenal, R. Gascón, V. Márquez-Álvarez, C. Blanco, R. M. Díaz I., ChemCatChem 2013, 5, 903-909.

[30] A. Mayoral, V. Gascón, R. M. Blanco, C. Márquez-Álvarez, I. Díaz, APL Mater. 2014, 2, 1133041-7.

[31] Victoria Gascón, Carlos Márquez-Álvarez, Isabel Díaz, Rosa M. Blanco "Hybrid ordered mesoporous materials as supports for permanent enzyme immobilization through non-covalent interaction", Chapter 19 pages 345-360 in: Non-covalent Interactions in the Synthesis and Design of New Compounds. Editors: Abel M. Maharramov, Kamran T. Mahmudov, Maximilian N. Kopylovich, Armando J. L. Pombeiro. (C) 2016 John Wiley \& Sons, Inc. ISBAN: 9781119109891.

[32] Jaeger, K-E.; Ransac, S.; Dijkstra, B. W.; Colson. Ch.; van Heuvel. M.; Misset, O. Fems Microbiol. Rev. 1994, 15; 29-63.

[33] Serra, E.; Mayoral, A.; Sakamoto, Y.; Blanco, R. M.; Diaz, I. Microporous Mesoporous Mater. 2008, 114, 201-213.

[34] Serra, E.; Díez, E.; Diaz, I.; Blanco, R. M. Microporous Mesoporous Mater. 2010, 132, 487-493.

[35] Gascón, V.; Díaz, I.; Blanco, R. M.; Márquez-Álvarez, C. $R S C A d v$., 2014, 4, 34356-34368.

[36] Mayer, A.M.; Staples, R.C. Phytochem. Rev. 2002, 60, 551-565. 
[37] Baldrian, P. FEMS Microbiol. Rev. 2006, 30, 215-242.

[38] Berka, R.M.; Schneider, P.; Golightly, E.J.; Brown, S.H.; Madden, M.; Brown, K.M.; Halkier, T.;Mondorf, K.; Xu, F. Appl. Environ. Microbiol. 1997, 63, 31513157.

[39] Tran, D.N.; Balkus, K.J. ACS Catal. 2011, 1, 956-968.

[40] Gascón, V.; Díaz, I.; Márquez-Álvarez, C.; Blanco, R.M. Molecules 2014, 19, 7057-7071.

[41] Gascón, V.; Márquez-Álvarez, C.; Blanco R. M., Appl. Catal A-Gen. 2014, 482, $116-126$.

[42] Lykourinou, V.; Chen, Y; Wang X. S.; Meng L.; Hoang, T.; Ming L.J.; Musselman R. L.; Ma S. J. Am. Chem. Soc. 2011, 133, 10382-10385.

[43] Deng, H.; Grunder, S.; Cordova, K.E.; Valente C.; Furukawa, H.; Hmadeh, M.; Gandara, F.; Whalley, A. C.; Liu, Z.; Asahina, S.; Kazumori, H.; O'Keeffe, M.; Terasaki, O.; Stoddart, J. F.; Yaghi, O. M. Science 2012, 336, 1018-1023.

[44] Gkaniatsou, E.; Sicard, C.; Ricoux, R.; Mahy, J. P.; Steuno, N.; Serre, C. Mater. Horizon. 2017, 4, 55-63.

[45] Mehta, J.; Bhardwaj, N.; Bhardwaj, S.K.; Kim, K.H. Coord. Chem. Rev. 2016, 322, $30-40$.

[46] Wu, X.; Hou, M.; Ge, J. Catal. Sci. Technol. 2015, 5, 5077-5085.

[47] Fried, D. I.; Brieler, F. J.; Froba, M. ChemCatChem 2013, 5, 862-884.

[48] Liu, W. L.; Lo, S. H.; Singco, B.; Yang, C. C.; Huang, H. Y.; Lin, C. H. J Mater Chem B 2013, 1, 928-932.

[49] Liu, W. L.; Yang, N. S.; Chen, Y. T.; Lirio, S.; Wu, C. Y.; Lin, C. H.; Huang, H. Y. Chem. Eur. J. 2015, 21, 115-119.

[50] Shieh, F. K.; Wang, S. C.; Yen, C. I.; Wu, C. C.; Dutta, S.; Chou, L. Y.; Morabito, J. V.; Hu, P.; Hsu, M. H.; Wu, K. C.; Tsung, C. K. J. Am. Chem. Soc. 2015, 137, 4276-4279.

[51] Sontz, P. A.; Bailey, J. B.; Ahn, S; Tezcan, F. A. J. Am. Chem. Soc. 2015, 137, 11598-11601.

[52] Fujita, D.; Fujita M. ACS Cent. Sci. 2015, 1, 352-353. 
[53] Sánchez-Sánchez, M.; Díaz, I; Getachew, N.; Chebude, Y. ES Patent 2012, P2012231968.

[54] Sánchez-Sánchez, M.; Getachew, N.; Díaz, K.; Díaz-García, M.; Chebude, Y; Díaz, I. Green Chem. 2015, 17, 1500-1509.

[55] Sánchez-Sánchez, M.; de Asua I.; Ruano, D.; Díaz, K. Cryst. Growth Des. 2015, $15,4498-4506$.

[56] Guesh, K.; Caiuby, C. A. D.; Mayoral, A.; Díaz-García, M.; Díaz, I.; SánchezSánchez, M. Cryst. Growth Des. 2017, 17, 1806-1813.

[57] Castro-Miguel, E.; Gascón, V.; Sánchez-Sánchez, M.; Blanco, R. M.; Díaz-García, M. PCT/ES 2016/070397, WO Patent 2016193516.

[58] Gascón, V.; Castro-Miguel, E.; Diaz-Garcia M.; Blanco, R. M.; Sánchez-Sánchez, M. J. Chem. Technol. Biotechnol. 2017, doi: 10.1002/jctb.5274.

[59] Gascón, V.; Carucci, C.; Jimenez, M. B.; Blanco, R. M.; Sánchez-Sánchez, M,; Magner, E. ChemCatChem 2017, 9, 1182-1186. 